(2) Open Access Full Text Article

\title{
Assessment of the Frequency of Depressive Symptoms in Epileptic Children (Single Center Study)
}

\author{
Nageh Shehata' \\ Salah Mahmoud Saleh' \\ Ahmed M Kamal ${ }^{2}$ \\ Omnia Kamal Awad' \\ 'Department of Pediatrics, Faculty of \\ Medicine, Minya University, El Minya, \\ 6III I, Egypt; ${ }^{2}$ Department of Neurology, \\ Faculty of Medicine, Minya University, El \\ Minya, Egypt
}

Background: Epilepsy, the most common neurological disorder in children, may present with many psychiatric comorbidities, the most common of which is depression.

Aim of the Work: We evaluated the frequency of depressive symptoms in epileptic children, with regard to the possible association between depression and their demographic data or seizure-related variables.

Patients and Methods: This cohort study was conducted on 80 children (6-13 years old) diagnosed as idiopathic epilepsy and were regularly recruiting the pediatric neurology clinic at Minya University Children Hospital. The Structured Birleson Depression Scale Questionnaire was used for assessment of presence of depressive symptoms, and Quality Of Life in Epilepsy (QOLIE-31) score was used to assess quality of life in those patients.

Results: Depressive symptoms were found in $37.5 \%$ of enrolled patients. There were statistically significant differences between the patients with depressive symptoms and the other group regarding age $(p=0.001)$, residence $(p=0.006)$ and past history of mood disorders ( $p=0.03$ ). Sleep disturbance was the highest predictor of depression in cases with depressive symptoms, detected in $90 \%$ of cases, followed by appetite disturbance in $86.6 \%$ of cases, while delusions and hallucinations were the lowest, detected in only $10 \%$ of cases. Both duration of epilepsy and frequency of seizures were significantly higher in cases with depressive symptoms than the other group $(p=0.001)$ for both. QOLIE score was significantly lower in cases with depressive symptoms than the other group ( $p=0.01$ for all).

Conclusion: Depressive symptoms are common in epileptic children, and it is often challenging and underestimated. It should be screened during the management of such children. Early diagnosis and more comprehensive package of care for depression in epileptic children will enable them to have a better quality of life.

Keywords: depressive symptoms, epileptic children, quality of life

\section{Introduction}

Epilepsy is a chronic neurological disorder which commonly affects children. The impact of epilepsy on patient's life style can be greater than the impact of seizures itself ${ }^{1}$ Most cases of epilepsy can be treated efficiently by medications, and affected children are expected to have a normal life. However, careful monitoring of such children for psychopathology and learning disability is needed, as both of these comorbidities are more common in epileptic children than in the general population. ${ }^{2}$ Depression is one of the common comorbidities of epilepsy, that is under-recognized and under-diagnosed. ${ }^{3,4}$ According to the Isle of Wight study, the percentage of depression in the pediatric age
Correspondence: Nageh Shehata Pediatric Department, Minia Children Hospital, El Minya, 6IIII, Egypt Email nagehismael@yahoo.com 
group was $0.2 \%$ in 10 years old and $2 \%$ in 14 years old. ${ }^{5}$ A higher rate of $1-5 \%$ among children and adolescents had been reported in other studies. ${ }^{6}$ In US, one of four children with epilepsy has depression and/or anxiety. ${ }^{7}$ Risk factors for depression in epilepsy include psychological and biological risk factors. ${ }^{8}$ The diagnostic criteria for depression were updated based on the new DSM- $5 .{ }^{9}$

According to these criteria, five or more symptoms of depression should be present most of the day, every day during one-two week period. The relationship between epilepsy and depression is bi-directional. It is stated that epilepsy may lead to depression through chronic stress exposure, in which stressful life events and inherent vulnerability affect the likelihood of developing depression. Conversely, depression may facilitate the development of epileptic activity through hyperactivity of the hypothalamic-pituitary-adrenal axis and disturbances of glutamate and G-amino butyric acid neurotransmitters. ${ }^{10}$ Depression in children can be particularly difficult to recognize, so clinicians need to look for less common symptoms of depression such as irritability, somatic complaints, concentration problems and poor school performance. ${ }^{11}$ A high index of suspicion for depression as a comorbid condition in epileptic children should be thought during management of such cases. Early diagnosis and more comprehensive packages of care for depression in epileptic children will enable them to have a better quality of life. ${ }^{12}$ We evaluated the percentage of depressive symptoms in epileptic children, with regard to the possible association between depression and their demographic data or seizure-related variables.

\section{Patients and Methods}

This cohort study was conducted on 80 children (6-13 years) attended the pediatric neurology outpatient clinic, Minya University Children Hospital over the period from January to June 2016. The enrolled patients were previously diagnosed and established as epileptics and they were reclassified according to new 2017 International League Against Epilepsy (ILAE) ${ }^{13}$ and furtherly categorized as idiopathic epilepsy which is defined as recurrent epileptic seizures not associated with structural brain lesions on MRI or abnormal neurological symptoms and/or signs interictally and implies normal neuropsychological status. ${ }^{14}$

\section{Exclusion Criteria}

1. All patients proved to be secondary epilepsy (by history, clinical examination, radiographic assessment, metabolic or genetic profiling) were excluded. 2. Patients with any physical disability including other comorbid neurological conditions, chronic medical illnesses or serious perception impairments like hearing and visual problems.

3. Psychiatric comorbidity other than depression. [After reviewing their files]

4. Clinically below an average intelligence. [From parents' comments and/or school performance and previous IQ report].

The study was conducted according to the principles of Helsinki and was revised, coded and approved by the Faculty of Medicine, Minia University Ethical Committee. After explanation of the aim of the study and the tools used, written informed consents were obtained from patients, caregivers. The interview of each patient was completed in a single setting using Depression Self-Rating Scale for Children (DSRS), ${ }^{15}$ to assess whether a diagnosis of a depressive disorder is present or not, then Quality of Life In Epilepsy (QOLIE) scale ${ }^{16}$ to assess health-related quality of life in these children. DSRS is an eighteen items self-administered tool designed to assess children with epilepsy for depression. Each item is rated on 3 point Likert scale with rating as 1 - never, 2 - sometimes, 3 always/often. Responses to items are simply scored in the direction of disturbance: Depressive items score 2, sometimes items score 1 , and none - depressive items score 0 , then the scores were summed to give the total score.

A score of 17 and higher is suggestive of the possibility of a major depressive disorder. The QOLIE-31 scale consists of 31 items which are in the form of 7 subscales which are seizure worry (5 items), emotional wellbeing (5 items), energy/fatigue (4 items), cognitive functioning (6 items), medication effects (3 items), social functioning (5 items) items), overall QOL (2 items) and overall health (one item). The responses used Likert rating scales which were later transformed into linear scales that ranged between 0 and 100, and the higher the score, the better is the quality of life. A short psychiatric sheet was taken which included demographic data, past history, family history and present mental state, in addition to the onset, course, and duration of depressive symptoms. Clinical data of epilepsy were obtained from the patient's epilepsy file in the clinic. The details taken from the epilepsy file included the age of onset of epilepsy, date of the last attack (less or more than 6 months ago), seizure type (focal with or without impaired awareness) or generalized), seizure frequency during the past year, antiepileptic medications (mono therapy/polytherapy), the electroencephalogram (EEG) findings (normal/abnormal EEG defined as photo paroxysmal response, occipital intermittent rhythmic delta 
activity, poly spikes, and poly spike-wave discharges $)^{17}$ and the medical and neurological examination findings. In addition, pre-written questions exploring how the epilepsy affects the educational and social lives of the enrolled patients were asked.

\section{Administration and Scoring}

Children or parents [in case of younger kids who could not fill the questionnaire] were asked to tick the column that applied to children during the last week.

According to depression self-rating scale for children (DSRS), patients were subdivided into two groups: Group (A): 30 Patients with idiopathic epilepsy and comorbid depression and group (B): 50 patients with idiopathic epilepsy without comorbid depression.

\section{Statistical Analysis}

Data were collected, revised and analyzed by using SPSS (Statistical Package for Social Science, version 22). Numerical data were expressed as mean and standard deviation (SD). Non numerical data were presented as number $(\mathrm{N})$ and percentage (\%). For normally distributed variables, Student's $t$-test was used for comparison between the two study groups while qualitative variables and those who were not normally distributed were analyzed by using Chi-Square ( $x^{2}$ test). A significant statistical test result was considered with $\mathrm{P}$ value less than 0.05 . The Correlation coefficient was used to relate two numerical variables while Pearson correlation was applied to assess the strength of association between two variables. The ( $\mathrm{r}$ ) ranged from $(-1:+1)$ : where 00.00 to 0.24 denotes weak or no association, 0.25 to 0.49 , fair association, 0.50 to 0.74: moderate association, and $0.75+$ : strong association.

\section{Results}

Out of 80 children with idiopathic epilepsy enrolled in this study, depressive symptoms were detected in 30 of them (37.5\%) (Table 1). Epileptic children showed significant increase in, age $(p=0.001)$, residence in rural areas $(p=0.006)$, and past history of mood disorders $(p=0.03)$ compared to the epileptic patients without depressive symptoms (Table 1). Sleep disturbance was the highest predictor of depression in cases with depressive symptoms, detected in $90 \%$ of cases, followed by appetite disturbance in $86.6 \%$ of cases, while delusions and hallucinations, were the lowest, detected in only $10 \%$ of cases (Figure 1). Children with depressive symptoms had both a duration of epilepsy more than 3 years, and more frequent seizures compared to the other group ( $p=0.001$ for both), while there was no significant difference between the two groups regarding the other clinical epilepsy-related variables, eg, age at onset, type of seizures, and

Table I Comparison Between the 2 Studied Groups Regarding the Socio-Demographic Data

\begin{tabular}{|c|c|c|c|c|c|}
\hline \multicolumn{2}{|l|}{ Variable } & \multirow{2}{*}{$\begin{array}{c}\text { All Patients } \mathbf{N}=\mathbf{8 0} \\
\mathbf{N}(\%)\end{array}$} & \multirow{2}{*}{$\frac{\text { Group (A) N=30 }}{\mathbf{N}(\%)}$} & \multirow{2}{*}{$\begin{array}{c}\text { Group (B) N=50 } \\
N(\%)\end{array}$} & \multirow[t]{2}{*}{ P-value } \\
\hline & & & & & \\
\hline Age & $\begin{array}{l}\text { Range } \\
\text { Mean } \pm \text { SD }\end{array}$ & $\begin{array}{c}6-13 \\
11.25 \pm 1.89\end{array}$ & $\begin{array}{c}10-13 \\
13.3 \pm 1.1\end{array}$ & $\begin{array}{c}6-9 \\
10 \pm 0.83\end{array}$ & $>0.001$ \\
\hline Sex & $\begin{array}{l}\text { Males } \\
\text { Females }\end{array}$ & $\begin{array}{l}34(42.5 \%) \\
46(57.5 \%)\end{array}$ & $\begin{array}{l}11(36.7 \%) \\
19(63.3 \%)\end{array}$ & $\begin{array}{l}23(46.0 \%) \\
27(54.0 \%)\end{array}$ & $>0.4$ \\
\hline Residence & $\begin{array}{l}\text { Urban } \\
\text { Rural }\end{array}$ & $\begin{array}{l}45(56.3 \%) \\
35(43.7 \%)\end{array}$ & $\begin{array}{l}\text { II (36.7\%) } \\
19(63.3 \%)\end{array}$ & $\begin{array}{l}34(68.0 \%) \\
16(32.0 \%)\end{array}$ & $>0.006$ \\
\hline Educational level & $\begin{array}{l}\text { None } \\
\text { Primary } \\
\text { Preparatory } \\
\text { Vocational }\end{array}$ & $\begin{array}{l}20(25 \%) \\
20(25 \%) \\
26(32.5 \%) \\
14(17.5 \%)\end{array}$ & $\begin{array}{l}7(23.3 \%) \\
7(23.3 \%) \\
I 1(36.7 \%) \\
5(16.7 \%)\end{array}$ & $\begin{array}{l}13(26.0 \%) \\
13(26.0 \%) \\
15(30.0 \%) \\
9(18.0 \%)\end{array}$ & $>0.9$ \\
\hline Family history & $\begin{array}{l}\text { None } \\
\text { Of epilepsy only } \\
\text { Of mood disorders only } \\
\text { Positive for both }\end{array}$ & $\begin{array}{c}48(60 \%) \\
23(28.7 \%) \\
7(8.8 \%) \\
2(2.5 \%)\end{array}$ & $\begin{array}{l}17(56.7 \%) \\
7(23.3 \%) \\
6(20.0 \%) \\
0(0.0 \%)\end{array}$ & $\begin{array}{l}31(62.0 \%) \\
16(32.0 \%) \\
1(2.0 \%) \\
2(4.0 \%)\end{array}$ & $>0.3$ \\
\hline Past history of mood disorders & $\begin{array}{l}\text { Positive } \\
\text { Negative }\end{array}$ & $\begin{array}{l}26(32.5 \%) \\
54(67.5 \%)\end{array}$ & $\begin{array}{c}24(80.0 \%) \\
6(20.0 \%)\end{array}$ & $\begin{array}{c}2(6.7 \%) \\
48 \text { (93.3\%) }\end{array}$ & $>0.03$ \\
\hline
\end{tabular}




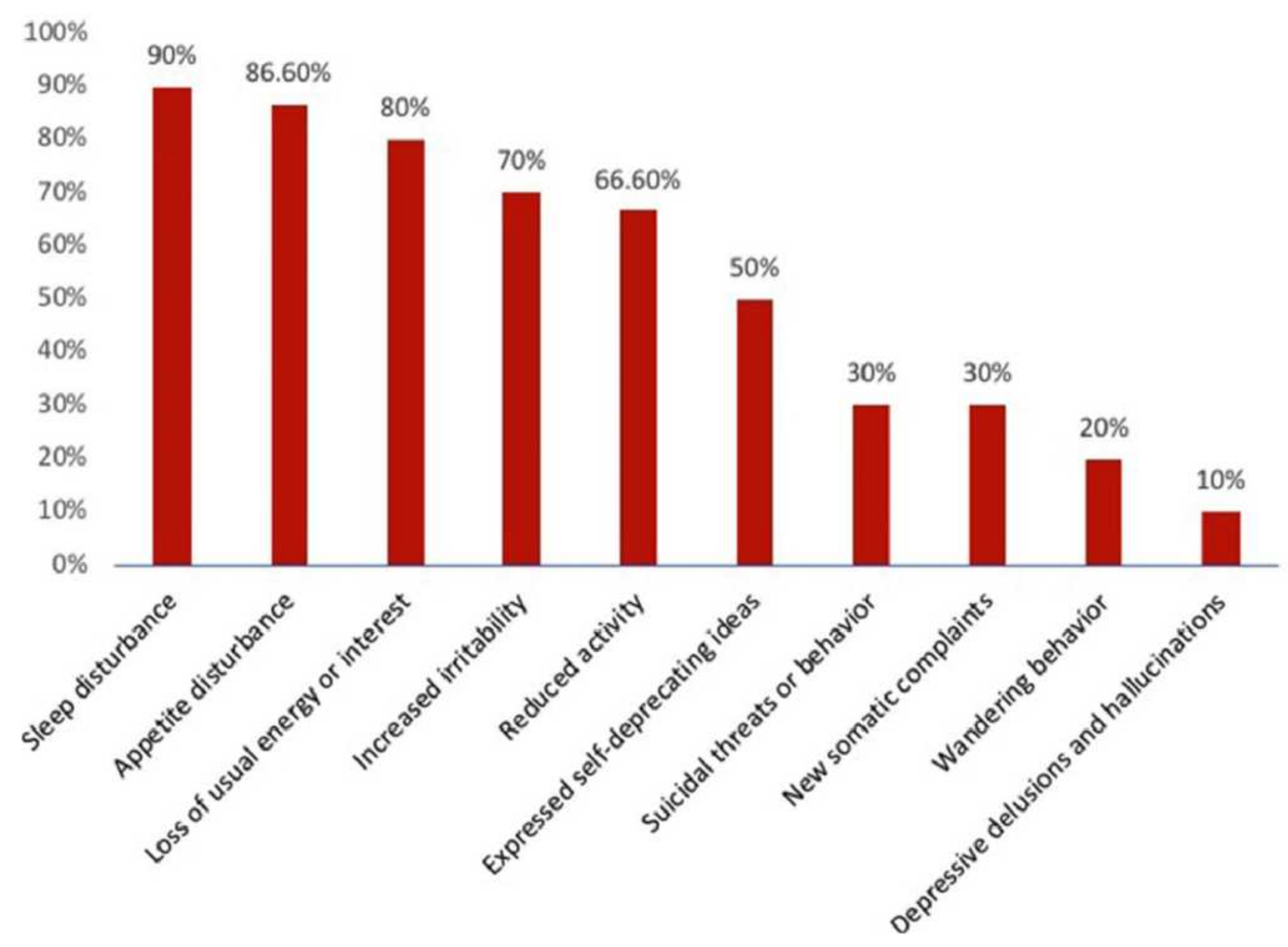

Figure I Types and frequency of depressive symptoms in the epileptic patients.

antiepileptic drugs used (Table 2, Figure 2). Depressive symptoms were more in patients whose frequent seizures occur in front of peers $(p=0.019)$ and in those with impaired social life $(p=0.04)$. Also, epilepsy had significant effect on both the social life and the education performance in patients with depressive symptoms compared to the other group ( $p=0.001,0.016$, respectively). (Table 3) There was impairment in all aspects of the (QOLIE-31) score in epileptic patients with depressive symptoms compared to the other group ( $p=0.01$ for all). (Table 4) A significant negative correlation between both the duration of epilepsy and frequency of seizures and Overall score of quality of life in patients with depressive symptoms compared to the other group was detected ( $p=$ 0.01 for both) (Figures 3-5).

\section{Discussion}

Epilepsy can have complex effects on the overall wellbeing or subjected quality of life in epileptic patients. ${ }^{18}$
Depression is one of the most frequent psychopathologies among epileptic individuals with difficult diagnosis and treatment. ${ }^{19}$ In our study, males represented $36.7 \%$ of those cases with depressive symptoms, while females represented $63.3 \%$. It was stated that the psychosocial and behavioral problems are more likely to occur in epileptic females than males. ${ }^{20-22}$ The mean age for cases with depressive symptoms, in our study, was significantly higher than the other group. In agreement with our finding, depression was more frequent in 12-18 years of age ${ }^{12}$ and it was diagnosed in $75 \%$ of epileptic adolescents (13-17 years) compared to $25 \%$ in those children aged less than 6 years. ${ }^{23}$ We found positive past history of mood disorder in $80 \%$ of the epileptic children with depressive symptoms. It was observed in adolescents with a major depressive disorder, that the risk of recurrence of the episode is approximately $40 \%$ at two years and $72 \%$ at five years. ${ }^{20}$ Suicidal ideation was found in $23.3 \%$ of epileptic patients with depressive symptoms, in the current study, which 
Table 2 Comparison Between the 2 Studied Groups Regarding the Clinical Epilepsy-Related Variables

\begin{tabular}{|c|c|c|c|c|c|}
\hline \multicolumn{2}{|l|}{ Variable } & \multirow{2}{*}{$\begin{array}{l}\text { All Patients } \\
\begin{array}{c}\mathbf{N}=\mathbf{8 0} \\
\mathbf{N}(\%)\end{array}\end{array}$} & \multirow{2}{*}{$\begin{array}{c}\text { Group (A) } \\
\begin{array}{c}\mathbf{N}=\mathbf{3 0} \\
\mathbf{N}(\%)\end{array}\end{array}$} & \multirow{2}{*}{$\begin{array}{c}\begin{array}{c}\text { Group (B) } \\
\mathbf{N}=\mathbf{5 0}\end{array} \\
\mathbf{N}(\%)\end{array}$} & \multirow[t]{2}{*}{$p$-value } \\
\hline & & & & & \\
\hline Age at onset (years) & Mean \pm SD & $1 I \pm 4.09$ & $11.53 \pm 3.53$ & $10.43 \pm 5.54$ & $>0.363$ \\
\hline \multirow[t]{2}{*}{ Duration of epilepsy } & $<3$ years & $43(53.8 \%)$ & $7(23.3 \%)$ & $36(72.0 \%)$ & $>0.01$ \\
\hline & $>3$ years & $37(46.3 \%)$ & $23(76.7 \%)$ & $14(28.0 \%)$ & \\
\hline \multirow[t]{2}{*}{ Type of seizure } & Partial & $20(25 \%)$ & 7 (23.3\%) & $13(26.0 \%)$ & $>0.79$ \\
\hline & Generalized & $60(75 \%)$ & $23(76.7 \%)$ & 37 (74.0\%) & \\
\hline \multirow[t]{2}{*}{ Seizure frequency } & Controlled [interval between seizures > Iyear] & $45(56.3 \%)$ & $7(23.3 \%)$ & $38(76.0 \%)$ & $>0.01$ \\
\hline & $\begin{array}{l}\text { Not controlled [interval between seizures < } \\
\text { lyear] }\end{array}$ & 35 (43.7\%) & $23(76.7 \%)$ & $12(24.0 \%)$ & \\
\hline \multirow[t]{2}{*}{ EEG findings } & Positive & $45(56.3 \%)$ & $20(66.7 \%)$ & $25(50.0 \%)$ & $>0.146$ \\
\hline & Negative & $35(43.7 \%)$ & $10(33.3 \%)$ & $25(50.0 \%)$ & \\
\hline \multirow[t]{8}{*}{ Antiepileptic drugs } & Mono-therapy & $4 \mathrm{I}(5 \mathrm{I} .2 \%)$ & $12(40.0 \%)$ & $29(58.0 \%)$ & $>0119$ \\
\hline & Poly-therapy & 39 (48.8\%) & $18(60.0 \%)$ & 21 (42.0\%) & \\
\hline & Carbamazepine & 51 (63.7\%) & $24(80 \%)$ & 27 (54\%) & \\
\hline & Sodium valproate & $48(60 \%)$ & $16(53.3 \%)$ & $32(64 \%)$ & \\
\hline & Phenytoin & $15(18.7 \%)$ & $6(20 \%)$ & $9(18 \%)$ & \\
\hline & Clonazepam & 30 (37.5\%) & $10(33.3 \%)$ & $20(40 \%)$ & \\
\hline & Phenobarbital & 15 (I8.7\%) & $5(16.7 \%)$ & $10(20 \%)$ & \\
\hline & Ethosuximide & $12(15 \%)$ & $4(13.3 \%)$ & $8(16 \%)$ & \\
\hline Seizure-free period & $<6$ & 59 (73.7\%) & $24(80.0 \%)$ & 35 (70.0\%) & $>0.325$ \\
\hline (months) & $>6$ & $21(26.3 \%)$ & $6(20.0 \%)$ & $15(30.0 \%)$ & \\
\hline
\end{tabular}

agrees with the opinion that adult patients with epilepsy are at higher risk for suicide and suicidal thoughts and attempts. $^{24,25}$ Epilepsy being a chronic disease, It can be a stressful factor, together with inability to deal with the condition that can cause psychological difficulties and emotional discomfort. $^{26}$ The percentage of depressive

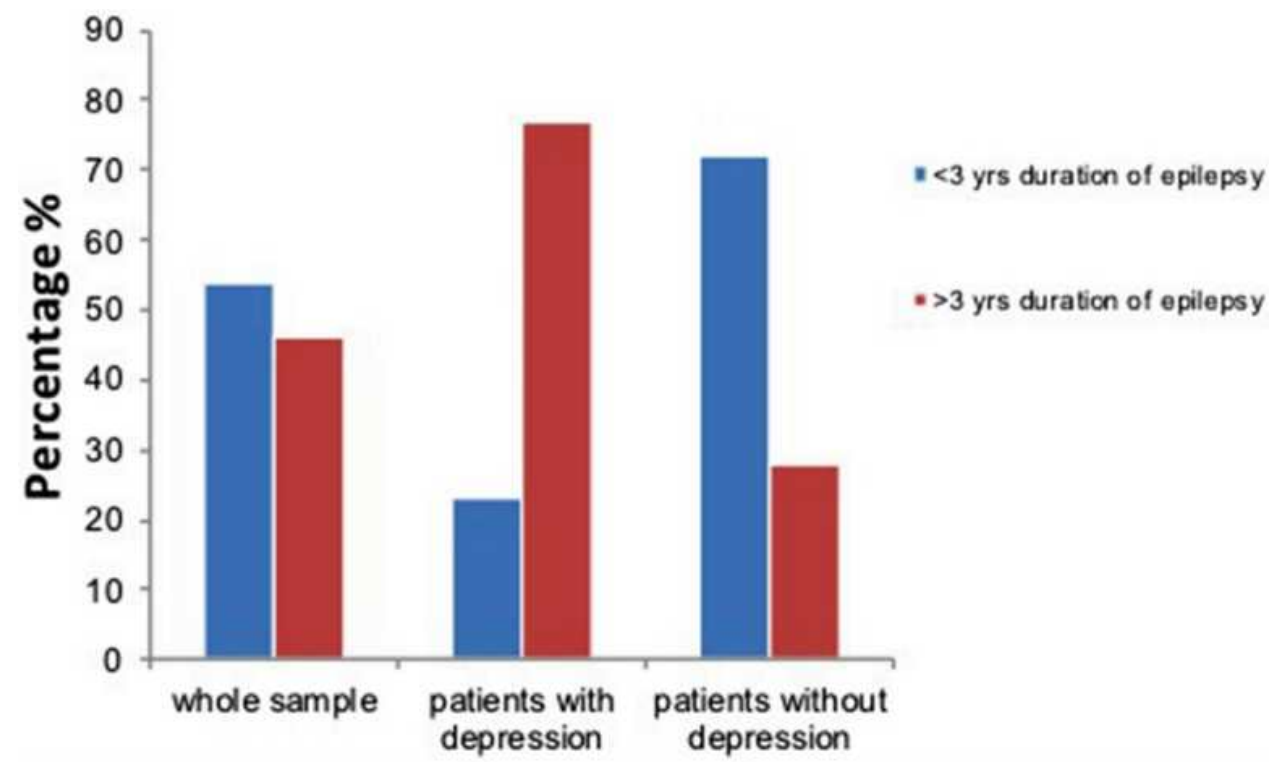

Figure 2 Distribution of patients according to the duration of epilepsy. 
Table 3 Comparison Between the 2 Studied Groups Regarding Variables of Epilepsy (Related to the Psychosocial Aspect)

\begin{tabular}{|c|c|c|c|c|c|}
\hline \multicolumn{2}{|l|}{ Variable } & \multirow{2}{*}{$\begin{array}{c}\text { All Patients } \mathbf{N}=\mathbf{8 0} \\
\mathrm{N}(\%)\end{array}$} & \multirow{2}{*}{$\frac{\text { Group (A) N=30 }}{\mathbf{N}(\%)}$} & \multirow{2}{*}{$\begin{array}{c}\text { Group (B) } \mathbf{N}=\mathbf{5 0} \\
\mathbf{N}(\%)\end{array}$} & \multirow[t]{2}{*}{$p$-value } \\
\hline & & & & & \\
\hline Seizures occurred in front of peers & $\begin{array}{l}\text { Yes } \\
\text { No }\end{array}$ & $\begin{array}{l}54(67.5 \%) \\
26(32.5 \%)\end{array}$ & $\begin{array}{c}25 \text { (83.3\%) } \\
5 \text { (16.7\%) }\end{array}$ & $\begin{array}{l}29(58.0 \%) \\
21(42.0 \%)\end{array}$ & $>0.019$ \\
\hline Affected patient's social life & $\begin{array}{l}\text { Yes } \\
\text { No }\end{array}$ & $\begin{array}{l}40(50 \%) \\
40(50 \%)\end{array}$ & $\begin{array}{c}22(73.3 \%) \\
8(26.7 \%)\end{array}$ & $\begin{array}{c}18(36.0 \%) \\
32(64 \%)\end{array}$ & $>0.001$ \\
\hline Affected patient's education & $\begin{array}{l}\text { Yes } \\
\text { No }\end{array}$ & $\begin{array}{l}47(58.7 \%) \\
33(41.3 \%)\end{array}$ & $\begin{array}{l}22(73.3 \%) \\
8(26.7 \%)\end{array}$ & $\begin{array}{l}25(50.0 \%) \\
25(50.0 \%)\end{array}$ & $>0.04$ \\
\hline Physical injury with seizures & $\begin{array}{l}\text { Yes } \\
\text { No }\end{array}$ & $\begin{array}{l}51(63.7 \%) \\
29(36.3 \%)\end{array}$ & $\begin{array}{c}23(76.7 \%) \\
7(23.3 \%)\end{array}$ & $\begin{array}{l}28(56.0 \%) \\
22(44.0 \%)\end{array}$ & $>0.063$ \\
\hline Urinary incontinence with Seizures & $\begin{array}{l}\text { Yes } \\
\text { No }\end{array}$ & $\begin{array}{l}35(43.8 \%) \\
45(56.3 \%)\end{array}$ & $\begin{array}{l}\text { I3 (43.3\%) } \\
17(56.7 \%)\end{array}$ & $\begin{array}{l}22(44.0 \%) \\
28(56.0 \%)\end{array}$ & $>0.954$ \\
\hline Suicidal tendency & $\begin{array}{l}\text { None } \\
\text { Wish } \\
\text { Ideation } \pm \text { Intent }\end{array}$ & $\begin{array}{l}64(80 \%) \\
9(11.3 \%) \\
7(8.7 \%)\end{array}$ & $\begin{array}{l}14(46.7 \%) \\
9(30.0 \%) \\
7(23.3 \%)\end{array}$ & $\begin{array}{c}50(100.0 \%) \\
0(0.0 \%) \\
0(0.0 \%)\end{array}$ & $<0.001$ \\
\hline
\end{tabular}

Table 4 Comparison Between the 2 Studied Groups Regarding the Mean Scores of Quality of Life in Epilepsy (QOLIE-3I)

\begin{tabular}{|c|c|c|c|}
\hline Variable & $\begin{array}{c}\text { Group (A) } \\
\qquad \mathbf{N}=30\end{array}$ & $\begin{array}{c}\text { Group (B) } \\
\qquad N=50\end{array}$ & P-value \\
\hline & Mean \pm SD & Mean \pm SD & \\
\hline Overall score & $59.53 \pm 17.59$ & $77.6 \pm 7.1$ & $<0.001$ \\
\hline Seizure worry & $51.82 \pm 32.77$ & $6.04 \pm 1.1$ & $<0.001$ \\
\hline Overall QOL & $54.27 \pm 12.67$ & $9.8 \pm 1.7$ & $<0.001$ \\
\hline $\begin{array}{l}\text { Emotional well- } \\
\text { being }\end{array}$ & $57.86 \pm 22.74$ & $11.7 \pm 1.8$ & $<0.001$ \\
\hline Energy/fatigue & $52.10 \pm 13.40$ & $9.8 \pm 1.2$ & $<0.001$ \\
\hline $\begin{array}{l}\text { Cognitive } \\
\text { functioning }\end{array}$ & $61.95 \pm 23.94$ & $21.3 \pm 3.3$ & $<0.001$ \\
\hline Medication effects & $88.08 \pm 22.92$ & $2.4 \pm 0.48$ & $<0.001$ \\
\hline Social functioning & $64.98 \pm 28.36$ & $16.2 \pm 2.6$ & $<0.001$ \\
\hline
\end{tabular}

symptoms among epileptic children in our study was $37.5 \%$. In another study, comorbid depression and disruptive disorders were present in $28.5 \%$ of epileptic patients. $^{20}$ This difference in percentage could be due to using different methods for assessing depression or difference in the sample size. The rate of depression according to parent-related instruments was $39.6 \%$, whereas in the self-report assessments for the same sample, it was $23 \%{ }^{20}$ This discrepancy may reflect the possibility that some epileptic children may not be fully aware of the impact of seizure on their lives. In our study, the duration of epilepsy was longer and frequency of seizures was more in patients with depressive symptoms than the other group. An association between duration of epilepsy, seizure frequency and depression was detected in many previous studies, ${ }^{12,27-29}$ while in our study, none of these variables (age at onset of epilepsy, type of seizure, mono therapy or poly therapy by antiepileptic drugs or the type of EEG findings) was found to be associated with depression in epileptic children. Similar observation was reported in other studies. ${ }^{30,31}$ In contrast, it was reported that children with recent onset epilepsy presented a higher rate of depressive disorders compared to controls. ${ }^{32}$ In our study, $73.3 \%$ of epileptic patients with depressive symptoms, thought that epilepsy affected their social life compared to $36 \%$ of other group, with statistically significant difference $(\mathrm{P}<0.001)$. This was also observed in other studies. ${ }^{23,24}$ Where it was found that patients with epilepsy and comorbid depression (of different age groups) have poorer quality of life across all scales, including social relations than those without depression. ${ }^{23,24}$ The duration of epilepsy, seizure type and seizure frequency were significantly correlated with the overall score of quality of life $(p<0.05)$. Epilepsy can have diverse and complex effects on the overall well-being or subjective quality of life in epileptic patients. ${ }^{18}$ It can be associated with profound physical, psychological and social consequence and 


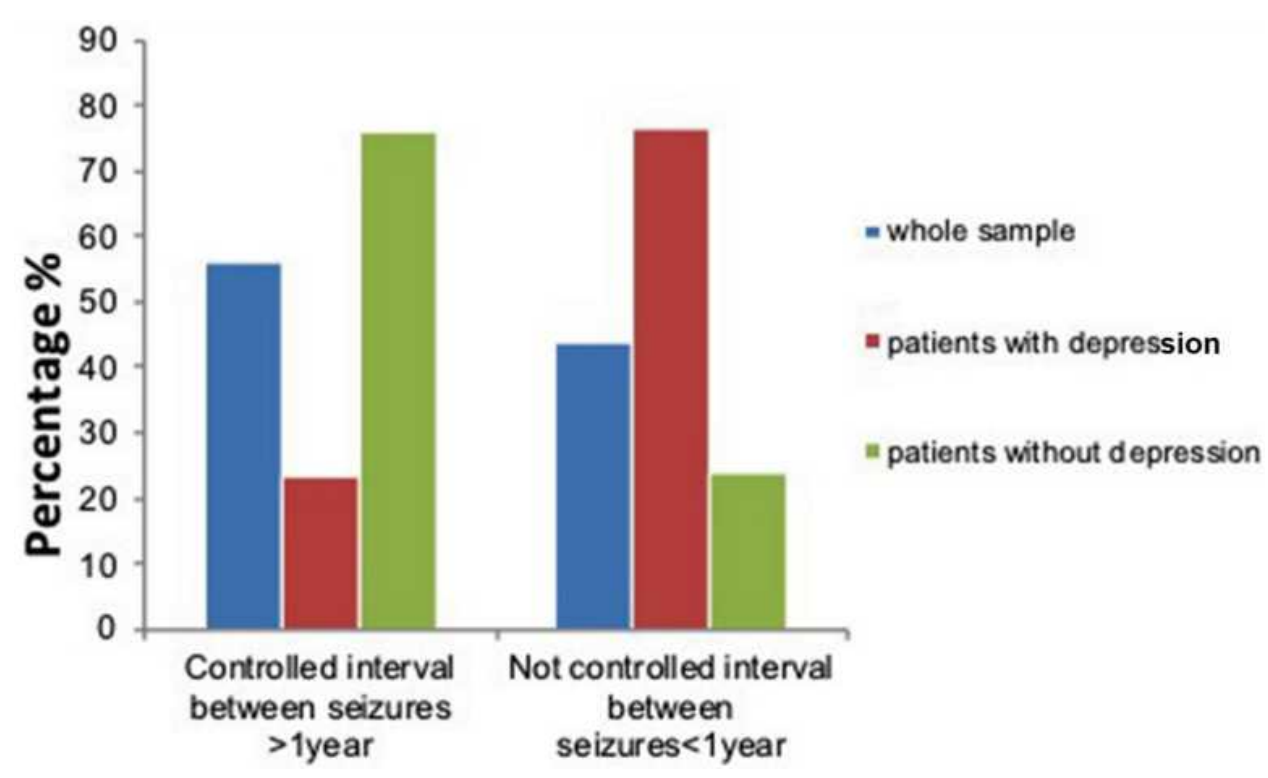

Figure 3 Distribution of patients according to the seizure frequency.

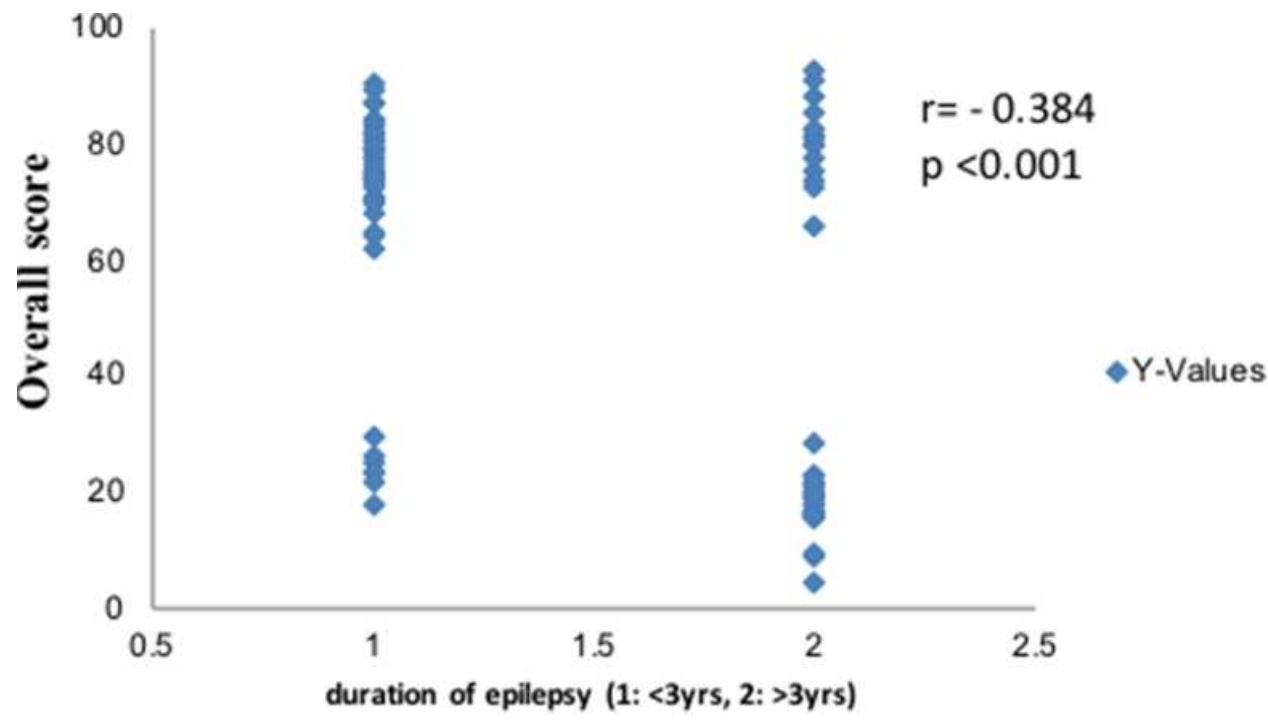

Figure 4 Correlation between duration of epilepsy and overall score of quality of life in epilepsy

its impact on the person's quality of life can be greater than that of some other chronic illnesses. ${ }^{33}$ In addition, frequency of seizures has been related to fear and misunderstanding which results in the social stigma and discrimination surrounding epilepsy. Also, it was reported that many patients with epilepsy were rejected by families and communities. ${ }^{34}$ In our study, depression affected all the domains of Quality of life in Epilepsy (QOLIE-31) in cases with depressive symptoms. Multiple studies have confirmed that mood is one of the strongest predictors of QOL, even when other factors as seizure severity or frequency are accounted. ${ }^{35}$ In our study, the duration of epilepsy was longer and frequency of seizures was more in patients with depressive symptoms. Major depression is associated with uncontrolled seizures, with prevalence twice than that of patients with controlled seizures. ${ }^{36}$ In the present study, the overall score of quality of life was significantly lower in epileptic patients with depressive symptoms compared to those without. This is consistent with other studies ${ }^{23,37}$ where epileptic patients with depression (of different age groups) were found to have poorer quality of life across all scales than those without depression. In addition, a review of several studies demonstrated that depression has been consistently associated 


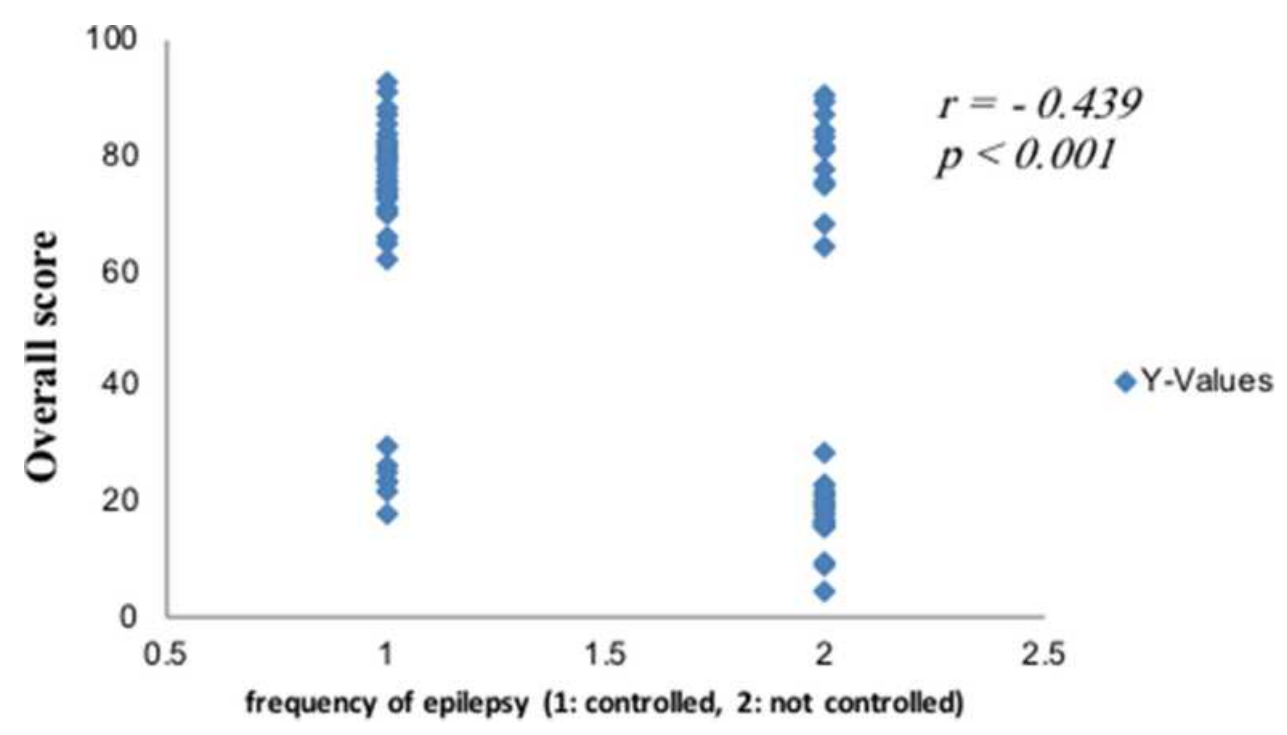

Figure 5 Correlation between frequency of epilepsy and overall score of quality of life in epilepsy.

with a poorer QOL in patients with epilepsy regardless of antiepileptic drug response. ${ }^{37}$

\section{Conclusion}

Depressive symptoms are commonly manifested in epileptic patients that are usually under estimated by the patients and their parents. A high index of suspicion screening for the estimation of depressive symptoms is required for early diagnosis and management of such cases. Seizure frequency and depressive symptoms are the most important players affecting the quality of life in epileptic patients.

\section{Study Limitations}

The lack of a control group, the low sample size, and the use of questionnaires for which some children could under estimating the depressive symptoms.

\section{Ethical Approval and Consent to Participate}

This study was conducted in accordance with the Declaration of Helsinki. All participants' caregivers were informed about the aim of our study. Written informed consents were obtained from patients' caregivers after revision and approval by Minia Faculty of Medicine Ethical Committee.

\section{Acknowledgment}

We would like to thank the physicians and nurses at Minya University Children Hospital, outpatient pediatric neurology clinic for their cooperation and sincere help during conduction of this research.

\section{Author Contributions}

All authors made substantial contributions to conception and design, acquisition of data, or analysis and interpretation of data; took part in drafting the article or revising it critically for important intellectual content; agreed to submit to the current journal; gave final approval of the version to be published; and agree to be accountable for all aspects of the work.

\section{Funding}

Personally funded by the authors.

\section{Disclosure}

The authors declare that they have no competing interests.

\section{References}

1. Johnston MV. Seizure in childhood. In: Vaughan VC, Behrman RE, editors. Nelson Textbook of Pediatrics. 20th ed. Philadelphia: Saunders; 2016:2457-2475.

2. Gelder M, Harrison P, Cowen P. Shorter Oxford Textbook of Psychiatry. 5th ed. Oxford: Oxford University Press; 2006.

3. Fecske E, Glasier P, Vargas Collado LM, Rende E. Standardized screening for depression in pediatric epilepsy. $J$ Pediatr Health Care. 2020;34(1):47-53. doi:10.1016/j.pedhc.2019.07.004

4. Plevin D, Smith N. Assessment and management of depression and anxiety in children and adolescents with epilepsy. Behav Neurol. 2019;2571368.

5. Harrington R. Affective disorders. In: Rutter M, Taylor E, editors. Child and Adolescent Psychiatry. Vol. 8. 4th ed. Oxford: Blackwell;2004:66-74.

6. Goodman R, Scott S. Management of depression and psychosis in children and adolescents with epilepsy. Child Psychiatry. 2005;9(7):76-92. 
7. LaGrant B, Marquis BO, Berg AT, Grinspan ZM. Depression and anxiety in children with epilepsy and other chronic health conditions: national estimates of prevalence and risk factors. Epilepsy Behav. 2020;103A:106828.

8. Rafie H, Alwasha MJ, Hussein B. Symptoms of anxiety and depression among adolescents with seizures in Irbid, Northern Jordan. Seizure. 2000;9(6):412-416. doi:10.1053/seiz.2000.0427

9. Uher R, Payne JL, Pavlova B, Perils RH. Major depressive disorders in DSM -5: implications for clinical practice and research of changes from DSM-IV. Depress Anxiety. 2013.

10. Buelow JM, Austin JK, Perkins SM, Shen J, Dunn DW, Fastenan PS. Behavior and mental health problems in children with epilepsy and low IQ. Dev Med Child Neurol. 2003;45:683-692. doi:10.1111/ j.1469-8749.2003.tb00871.x

11. Kanner A, Dunn D. Diagnosis and management of depression and psychosis in children and adolescents with epilepsy. J Child Neuro. 2004;19(1S):S65-72. doi:10.1177/088307380401900108

12. Oguz A, Kurul S, Dirik E, Eylül D. Relationship of epilepsy-related factors to anxiety and depression scores in epileptic children. $J$ Child Neurol. 2002;17(1):37-40. doi:10.1177/088307380201700109

13. Avakyam GN, Blinov DV, Lebedeva AV, Burd SG, Avakyan GG. ILAE classification of the epilepsies: epilepsy and paroxysmal conditions: the 2017 revision and update. Epilepsia. 2017;9(1).

14. Delgado-Escueta AV, Medina MT, Serratosa JM, et al. Mapping and positional cloning of common idiopathic generalized epilepsies: juvenile myoclonus epilepsy and childhood absence epilepsy. Adv Neurol. 1999;79:351-374.

15. Birleson P. The validity of depressive disorders in childhood and the development of a self-rating scale: a research report. J Psychol Psychiatry. 1981;22:73-88. doi:10.1111/j.1469-7610.1981.tb00533.x

16. Vickrey BG, Perrine KR, Hays RD, et al. Quality of Life in Epilepsy QOLIE-31 (Version 1.0): Scoring Manual and Patient Inventory. Santa Monica: Rand; 1993.

17. Markand ON. Pearls, perils, and pitfalls in the use of the electroencephalogram. Semin Neurol. 2003;23:7-46.

18. Sillanpaa M, Haataja L, Shinnar S. Perceived impact of childhood onset epilepsy on quality of life as an adult. Epilepsia. 2004;45:971-977. doi:10.1111/j.0013-9580.2004.44203.x

19. Kobau R, Gilliam F, Thurman D. Prevalence of self-reported epilepsy or seizure disorder and its associations with self-reported depression and anxiety: results from the 2004 Health Styles Survey. Epilepsia. 2006;47:1915-1921. doi:10.1111/j.1528-1167.2006.00612.x

20. Caplan R, Siddarth P, Gurbani S, Hanson R, Sankar R, Shields WD. Depression and anxiety disorders in pediatric epilepsy. Epilepsia. 2005;46(5):720-730. doi:10.1111/j.1528-1167.2005.43604.x

21. Turky A, Beavis J, Thapar A, et al. Psychopathology in children and adolescents with epilepsy: an investigation of predictive variables. Epilepsy Behav. 2008;12(1):136-144. doi:10.1016/j.yebeh.2007.08.003

22. Austin J, Osborne P, Beach J. Epilepsy familiarity, knowledge and perceptions of stigma: report from a survey of adolescents in the general population. Epilepsy Behav. 2002;3:368-375. doi:10.1016/ S1525-5050(02)00042-2

Risk Management and Healthcare Policy

\section{Publish your work in this journal}

Risk Management and Healthcare Policy is an international, peerreviewed, open access journal focusing on all aspects of public health, policy, and preventative measures to promote good health and improve morbidity and mortality in the population. The journal welcomes submitted papers covering original research, basic science, clinical \& epidemiological studies, reviews and evaluations,
23. Thome-Souza S, Kuczynski E, Assumpção F, et al. Which factors may play a pivotal role on determining the type of psychiatric disorder in children and adolescents with epilepsy? Epilepsy Behav. 2004;5:988-994. doi:10.1016/j.yebeh.2004.09.001

24. Gandy M, Sharpe L, Perry KN, et al. The psychosocial correlates of depressive disorders and suicide risk in people with epilepsy. J Psychosom Res. 2013;74(3):227-232. doi:10.1016/j.jpsychores. 2012.11.001

25. Hamed SA. Risks of suicidality in adult patients with epilepsy. World $J$ Psychiatry. 2012;2(2):33-42. doi:10.5498/wjp.v2.i2.33

26. De Souza E, Salgado P. A psychosocial view of anxiety and depression in epilepsy. Epilepsy Behav. 2006;8:232-238. doi:10.1016/j. yebeh.2005.10.011

27. Grabowska-Grzyb A, Jedrzejczak J, Nagańska E, Fiszer U. Risk factors for depression in patients with epilepsy. Epilepsy Behav. 2006;8:411-417. doi:10.1016/j.yebeh.2005.12.005

28. El-Alameey I, Monir Z, Eltahlawy E. Neuropsychological problems among epileptic children in Egypt. Med Res J. 2013;12(2):58-68. doi:10.1097/01.MJX.0000438375.05493.f7

29. Roeder R, Roeder K, Asma E, et al. Depression and mental health help seeking behaviors in a predominantly African American population of children and adolescents with epilepsy. Epilepsia. 2009;50 (8):1943-1952. doi:10.1111/j.1528-1167.2009.02046.x

30. Herman B, Seidenberg M, Bell B. Psychiatric comorbidity in chronic epilepsy: identification,consequences, and treatment of major depression. Epilepsia. 2000;41:S31-41. doi:10.1111/j.15281157.2000.tb01522.x

31. Robertson M, Trimble M, Townsend H. Phenomenology of depression in epilepsy. Epilepsia. 2007;28(4):364-372. doi:10.1111/j.15281157.1987.tb03659.x

32. Jones JE, Watson R, Sheth R, et al. Psychiatric comorbidity in children with new onset epilepsy. Dev Med Child Neurol. 2007;49 (7):493-497. doi:10.1111/j.1469-8749.2007.00493.x

33. International League Against Epilepsy. Out of the shadows: European declaration on epilepsy. Epilepsia. 2003;44:2-3.

34. Chomba EN, Haworth A, Atadzhanov M, Mbewe E, Birbeck GL. Zambian health care workers' knowledge, attitudes, beliefs, and practices regarding epilepsy. Epilepsy Behav. 2003;10:111-119. doi:10.1016/j.yebeh.2006.08.012

35. Jacoby A, Snape D, Baker GA. Determinants of quality of life in people with epilepsy. Neuro Clin. 2009;27:843-863. doi:10.1016/j. ncl.2009.06.003

36. Dias R, Bateman LM, Farias ST, et al. Depression in epilepsy is associated with lack of seizure control. Epilepsy Behav. 2010;19:445. doi:10.1016/j.yebeh.2010.08.029

37. Weigartze P, Seidenberg M, Woodard A, Gidal B, Hermann B. Co-morbid psychiatric disorder in chronic epilepsy: recognition and etiology of depression. Neurology. 1999;53(5 suppl 2):S3-8. guidelines, expert opinion and commentary, case reports and extended reports. The manuscript management system is completely online and includes a very quick and fair peer-review system, which is all easy to use. Visit http://www.dovepress.com/testimonials.php to read real quotes from published authors. 